\title{
ENSAIO CRÍTICO SOBRE AS POSSÍVEIS ESTRATÉGIAS ADOTADAS PARA O ENFRENTAMENTO AO FECHAMENTO DAS ESCOLAS PROVOCADO PELA COVID-19: rede municipal de ensino de Campinas (SP) - Brasil
}

\author{
Juliano Pereira de Mello \\ Pontifícia Universidade Católica de Campinas \\ Artur José Renda Vitorino \\ Pontifícia Universidade Católica de Campinas
}

\begin{abstract}
Resumo
O artigo apresenta uma análise crítica a partir das notas elaboradas pela organização da sociedade civil Todos pela Educação (2020): "Ensino a distância na educação básica frente à pandemia da COVID-19", pelo Banco Mundial (2020): "Políticas Educacionais na Pandemia da COVID-19: O que o Brasil pode aprender com o resto do mundo?" e dos dilemas verificados no âmbito da Rede Municipal de Ensino de Campinas (SP) em tempos de Pandemia Covid-19. A referida análise é construída a partir do aporte teórico sobre a finalidade da educação proposta por Biesta (2012), dos possíveis percalços causados pelo chamado "abstracionismo pedagógico" apresentado por Azanha (1992), das considerações sobre o conceito de "sem-domicílio" utilizado por Popkewitz e Lindblad (2016) e do arcabouço legal e normativo referente à educação básica na escala federal e municipal. Palavras-chave: Abstracionismo Pedagógico, Finalidade da Educação, Pandemia Covid 19, Campinas (SP), Educação Básica.
\end{abstract}

\begin{abstract}
The article presents a critical analysis based on the notes prepared by the civil society organization Todos pela Educação (2020): "Distance learning in basic education in the face of the COVID-19 pandemic", by the World Bank (2020): "Educational Policies in COVID-19 pandemic: What can Brazil learn from the rest of the world?" and the dilemmas found in the scope of the Campinas Municipal Education Network (SP) in times of Pandemia Covid-19. This analysis is built from the theoretical contribution on the purpose of education proposed by Biesta (2012), from the possible problems caused by the so-called "pedagogical abstractionism" presented by Azanha (1992), from the considerations on the concept of "homelessness" used by Popkewitz and Lindblad (2016) and the legal and normative framework referring to basic education at the federal and municipal scales.

Keywords: Pedagogical Abstractionism, Purpose of Education, Pandemic Covid 19, Campinas (SP), Basic Education.
\end{abstract}




\section{Introdução}

Tendo em vista as discussões sobre a finalidade da educação a partir da proposta elaborada por Biesta (2012), ou seja, discutindo o que pode ser considerado para definirmos uma "boa educação", a qual, nas últimas décadas, está quase que totalmente voltada e reduzida à mensuração e à comparação de resultados educacionais entre países, estados e municípios, os quais, no atual contexto de pandemia, tendem a ter suas desigualdades educacionais cada vez mais reveladas e ampliadas a partir, principalmente, da manutenção dos critérios que têm servido para caracterizar e medir a chamada "educação de qualidade".

Também ressaltamos os cuidados para evitarmos, ao máximo, a armadilha que Azanha (1992) denominou de "abstracionismo pedagógico", o qual se caracteriza pela leviandade de descrever, explicar ou compreender situações educacionais reais, desconsiderando as determinações específicas de sua concretude, para ater-se apenas a "princípios" ou "leis" gerais que, nas suas abrangências abstratas são, aparentemente, suficientes para dar conta das situações analisadas, porém, acabam sendo evidenciadas em suas limitações, principalmente, agravadas quando nos deparamos com as situações de exceção impostas em um contexto de calamidade pública, ou mesmo, de isolamento social permeado por uma grande diversidade de situações encontradas em cada sistema de ensino e, principalmente, em cada escola e sua comunidade formada por profissionais, alunos(as) e famílias.

Consideramos também o conceito de "sem-domicílio" utilizado por Popkewitz e Lindblad (2016, p.739), os quais esclarecem que essa ideia envolve abstrações sobre a existência de uma distinção humana, que parece não ter um lugar histórico, uma especificidade cultural e limites geográficos, ou seja, trata-se de uma abstração que propõe e/ou pressupõe um aluno universal, um professor universal, uma escola universal e, consequentemente, um cidadão universal, como que genérico e estereotipado - que remete à um padrão de educação e ensino universal.

Então, ainda ressaltando esse tempo da busca por soluções que respondam aos impactos da Pandemia Covid-19 na educação mundial e, aqui, mais especificamente, tratando das ações na escala do sistema municipal de ensino de Campinas (SP), propomos a análise dos documentos supracitados na perspectiva de nos comprometermos com o que Biesta (2012, p.813-814) chama de valores últimos da educação, ou seja, valores acerca de objetivos e propósitos da educação, para além de uma educação tida como eficaz por atender, muitas vezes, de forma consensualmente imposta, muito mais aos interesses de alguns grupos hegemônicos em detrimento de outros que são diretamente afetados pelas decisões, porém anulados em suas possibilidades de construírem outras propostas e práticas que atendam as diferentes realidades escolares. 


\section{As notas simples para uma questão complexa: Banco Mundial e Todos pela Educação}

Na nota do Banco Mundial (2020): "Políticas Educacionais na Pandemia da COVID-19: O que o Brasil pode aprender com o resto do mundo?", são apresentadas experiências internacionais para mitigar os efeitos da pandemia da COVID-19 na educação, as quais seriam exemplos exitosos para as ações a serem adotadas pelos sistemas de ensino brasileiros: Federal, Estaduais e Municipais.

Ressaltamos que o Banco Mundial (2020), ao indicar o que as "redes de educação" podem fazer para promover aprendizagem e tempo pedagógico de forma equitativa, mesmo com as escolas fechadas, utiliza, indistintamente os seguintes termos: "educação a distância", “ensino a distância", aprendizagem a distância", "aulas a distância" e "ensino EaD”, os quais, associa às atividades e ferramentas, que dependem das condições de conectividade, principalmente, por meio de acesso a internet (Banco Mundial, 2020, p.2).

Além disso, o Banco Mundial (2020) apresenta dados que revelam a grande desigualdade socioespacial brasileira (por região político-administrativa e na comparação entre os espaços urbano e rural) com relação ao apoio das famílias ao estudo das crianças em casa, conforme dados do SAEB (2017), do uso da internet em sala de aula, conforme Censo Escolar (2019) e da presença de computadores, tablets e celulares nos domicílios brasileiros, conforme PNAD contínua (2017).

Porém, o Banco Mundial (2020), mesmo frente aos dados supracitados e sem apresentar informações sobre as efetivas condições de acesso domiciliar à internet no Brasil, ao indicar o que as experiências internacionais dizem da implementação de educação a distância em um cenário denominado de "baixa capacidade" (Banco Mundial, 2020, p.3), ainda ressalta a importância da avaliação da infraestrutura e capacidade dos estudantes e professores de se adaptarem às tecnologias de ensino a distância, o qual, está totalmente voltado às ações que considerem "... distintos caminhos de ensino a distância com aulas virtuais por meio da internet, além da distribuição de materiais impressos para os alunos". (Banco Mundial, 2020, p.03)

Por fim, destacamos abaixo um trecho em que o Banco Mundial (2020, p.3), fazendo uso da expressão "ensino EaD”, justifica com três argumentos as dificuldades de uma suposta transição internacional para o ensino a distância:

A evidência internacional mostra que esse efeito negativo na transição para o ensino a distância ocorre devido: (i) à falta de familiaridade com as ferramentas utilizadas no ensino $\mathrm{EaD}$, (ii) à falta de um ambiente familiar motivador ao aprendizado online bem-sucedido, (iii) e à falta de congruência entre o que antes era ensinado em sala de aula e o que passa a ser ensinado online.

Em seguida, considerando a nota técnica "Ensino a distância: Educação Básica frente à pandemia da Covid-19" da Organização da Sociedade Civil Todos pela educação (TPE, 2020), a mesma começa ressaltando ser a primeira versão (abril de 2020) e reconhecendo que 
é um documento em construção tendo em vista as novas discussões e contribuições advindas das experiências nacionais e internacionais, bem como esclarecendo que a bibliografia educacional disponível está com a maior parte de seus estudos proveniente de tempos de normalidade, e não excepcionais como agora, ao passo que nenhuma solução é, em um contexto como o atual, perfeita e definitiva. (TPE, 2020, p.02)

Conforme dados da UNESCO (2020 apud TPE, 2020, p.03), as medidas de distanciamento social no atual contexto de Pandemia Covid-19, na Educação, de maneira geral, levaram ao fechamento de escolas públicas e particulares, com interrupção de aulas presenciais. Sendo que, $91 \%$ do total de alunos do mundo e, mais de 95\% da América Latina estão, temporariamente, "fora da escola" devido à Covid-19.

Cabe esclarecer que o termo "fora da escola" presente no parágrafo anterior, não significa evasão escolar, mas, refere-se ao fato de não estarem frequentando o prédio escolar, pois as matrículas dos estudantes estão mantidas e a responsabilidade por suas vidas escolares continua sendo assegurada na relação com a escola, a qual, nesse contexto de total exceção pandêmica, tem sido realizada por meio do chamado ensino a distância.

Além disso, a nota apresenta dados (de 03 de abril de 2020) revelando que as chamadas redes estaduais, são aquelas que mais têm avançado em transferir aulas e outras atividades pedagógicas para formatos a distância, por meio, principalmente, da disponibilização de plataformas online, aulas ao vivo em redes sociais e envio de materiais digitais aos alunos.

Cabe destacar que, ao contrário do uso indiscriminado de termos como na nota do Banco Mundial, a nota do TPE (2020) esclarece a opção pelo uso de termos como ensino a distância e ensino remoto, em vez da terminologia "Educação a Distância - EaD", se dá pelo fato da:

compreensão de alguns especialistas (Craig, 2020 e o Centro de Inovação para a Educação Brasileira - CIEB) de que a EaD, conforme legislações brasileiras recentes (Decreto no 9.057/2017), deve ser entendida como uma modalidade de ensino mais estruturada, que pressupõe uma organização própria de currículo, materiais de apoio e avaliação, enquanto os esforços atuais têm sido mais pontuais, de reação à crise que se impôs.(TPE, 2020, p.03)

Segundo o TPE (2020), a nota buscou evitar o que chamaram de "leitura fria" das pesquisas sobre ensino a distância, as quais, em geral, se concentram em comparar "aulas a distância" com "aulas presenciais", pois no contexto atual, a questão é, fundamentalmente, uma discussão entre "aulas a distância" e a "não realização de aulas", o que, inclusive, para melhor elucidarem seu posicionamento frente a esse dilema, apontam similaridade com experiências de países que interromperam o funcionamento de escolas por longos períodos devido a situações de guerra, crises de refugiados, desastres naturais e epidemias, nas quais, segundo a referida nota, a escolha do poder público em nada fazer, sob o argumento de que não é possível chegar em todos, tende a aumentar as desigualdades resultantes da situação de emergência.

A nota do TPE $(2020$, p.04) revela que a maioria das chamadas redes estaduais está utilizando como estratégia de ensino a distância, principalmente, as plataformas online, ao 
passo que, as chamadas redes municipais, em sua maioria, não estão oferecendo nenhuma opção das onze estratégias pesquisadas.

O recorte da pesquisa e análise apresentada pela nota do TPE (2020) em relação ao ensino fundamental e ensino médio, segundo esse mesmo documento, exclui a primeira etapa da Educação Básica - a Educação Infantil (Creche e Pré-Escola) - devido ao entendimento de que a dinâmica educacional para crianças de 0 a 5 anos difere demasiadamente das dinâmicas nas etapas subsequentes. Assim, merecendo uma abordagem e análise específicas quanto à pertinência de atividades a distância em situações de fechamento provisório de escolas.

A nota do TPE (2020, p.05) aponta quatro mensagens que objetivam, prioritariamente, qualificar o debate público educacional, a saber: a) as soluções de ensino remoto podem contribuir e devem ser implementadas, porém, desde já, com a devida atenção ao planejamento de volta às aulas; b) uma estratégia consistente para o ensino remoto é aquela que busca mitigar as condições heterogêneas de acesso e os diferentes efeitos de soluções a distância em função do desempenho prévio dos estudantes; c) Ensino remoto não é sinônimo de aula online, ou seja, há diferentes maneiras de estimular a aprendizagem a distância e, se bem estruturadas, atividades educacionais podem cumprir mais do que uma função puramente acadêmica; d) Mesmo a distância, atuação dos professores é central.

\subsection{Uma breve análise das notas}

Ao compararmos a utilização dos dados sobre as características de escolas, estudantes, professores e famílias brasileiras com relação ao acesso à internet, acesso a equipamentos de tecnologia da informação (TICs), de apoio familiar para o estudo em casa, de formação para trabalho com tecnologias educacionais para os professores e de escolas com equipamentos e uso de internet, ressaltamos que a nota do TPE (2020), embora apresente menos dados do que a nota do Banco Mundial (2020), acaba por considerar os dados apresentados com proposições que indicam a necessidade de se respeitar e atender de forma diversa as especificidades de cada lugar frente a grande desigualdade socioespacial brasileira, ou seja, segundo Popkewitz e Lindblad (2016, p.729-730), a crítica que pode ser feita às estatísticas educacionais não é em serem essencialmente "boas/más", sobre sua utilidade, ou viés; nem é para censurar ou condenar números ou estatísticas utilizadas na educação, mas, sobretudo, deve ser para colocar as propostas e ações em um contexto cultural, político (e espacial) mais amplo.

A nota do Banco Mundial (2020, p.02-03) cita três vezes que a educação brasileira passa por uma "transição repentina para ensino a distância" e que essa suposta transição, segundo evidências internacionais, teria um efeito negativo devido a aspectos relacionados à falta de familiaridade de professores e estudantes com as ferramentas utilizadas no ensino EaD, à falta de um ambiente familiar motivador ao aprendizado online bem-sucedido e à falta de congruência entre o que antes era ensinado em sala de aula e o que passa a ser ensinado online, de acordo com Popkewitz e Lindblad (2016, p.728), ressaltamos que tais afirmações colocam as populações vistas meramente como dados para identificar um campo de 
intervenção e planejamento social, a fim de trazer uma suposta melhoria social e progresso totalmente descontextualizada.

Sendo assim, as afirmações do Banco Mundial (2020) supracitadas, desconsideram totalmente uma abordagem diagnóstica e histórica em que:

questionar como, historicamente, os números tornam-se plausíveis e são considerados 'razoáveis', como uma maneira de pensar sobre política e investigação, e questionar sobre os limites de tal pensamento em questões sobre a inclusão e exclusão social. (Popkewitz; Lindblad, 2016, p.729)

Ressaltamos que os conceitos de "educação a distância", "ensino a distância" e "ensino remoto" são tratados, em certa medida, com mais cuidado na nota do TPE (2020), enquanto na nota do Banco Mundial (2020), os conceitos de "educação a distância", "ensino a distância", aprendizagem a distância", "aulas a distância" e "ensino EaD" são utilizados de maneira indiscriminada, sendo assim, além de demonstrar uma aparente falta de rigor conceitual na forma de apresentar as análises e propostas, bem como suas consequências, conforme a complexidade do tema, também remete-nos ao que Azanha (1992) chamou de "abstracionismo pedagógico", ou seja, a:

veleidade (leviandade) de descrever, explicar ou compreender situações educacionais reais, desconsiderando as determinações específicas de sua concretude, para ater-se apenas a 'princípios' ou 'leis' gerais que na sua abrangência abstrata seriam, aparentemente, suficientes para dar conta das situações focalizadas. (Azanha, 1992, p.42)

Sendo assim, podemos dizer que, além de encontrarmos marcas desse estilo de investigação educacional caracterizado como "abstracionismo pedagógico" (Azanha, 1992, p.42) na nota do Banco Mundial (2020), pois não conseguiram, de fato, mais do que utilizarem-se da teoria disponível para tentarem efetuar operações formais de classificação de "fatos" da realidade, ou seja, como se essas operações constituíssem explicações em si mesmas, consequentemente, resumindo a compreensão histórica na (mera) "aplicação" de "referenciais" a uma realidade, a qual, inclusive, parece ser negligenciada pelo documento, bem como, muito mal elaborada na maneira de uso dos conceitos.

Segundo Azanha (1992, p.43), muitas vezes, o "abstracionismo pedagógico" é apenas uma forma ingênua de encaminhamento do exame de um assunto, no qual o estudo da realidade é substituído por um jogo verbal semanticamente vazio, porém, outras vezes, o abstracionismo mais parece ser um claro golpe de astúcia, ideológica ou não.

Então, dado o atual contexto de total exceção na educação mundial e brasileira causado pela Pandemia Covid-19, mais do que nunca, ressaltamos, assim como Azanha (1992, p.45), a necessidade das pesquisas sobre a educação brasileira e suas consequentes análises, fundamentarem-se em cuidadosos e preliminares estudos descritivos, com uma abordagem histórica da instituição escolar e, assim, sermos capazes de captar as efetivas transformações 
que ocorreram nas últimas décadas e, de forma repentina nos últimos meses, as necessidades adaptativas momentâneas que estão ocorrendo nesse momento excepcional, consequentemente, fazendo com que a escola brasileira seja estudada como uma entidade concreta, completamente ligada a uma ambiência histórica.

Sendo assim, Azanha (1992, p.47) também nos adverte que:

o fato de que essa espécie de discurso abstrato sobre educação tem um efeito paralisante sobre a própria ação educativa. Pois, negando-se qualquer grau de autonomia às práticas escolares concretas e considerando-as invariavelmente como mero resíduo de forças exteriores a elas, eventuais características que assumam num certo momento só seriam modificáveis por alterações nessas forças e nunca por uma mudança interior nas próprias práticas. (Azanha, 1992, p.47)

No sentido de considerar os possíveis efeitos paralisantes supracitados em função dos "abstracionismos pedagógicos" que ignoram as diferentes práticas escolares enquanto possibilidades reais de promoção da educação a partir de diferentes estratégias de ensino, temos que, embora as notas aqui analisadas não apresentem definições sobre os princípios da educação e seus objetivos, pois mencionam tão somente a manutenção do processo ensinoaprendizagem, a nota do TPE (2020), mapeou 11 estratégias de ensino a distância (digitais e analógicas), ao passo que, a nota do Banco Mundial (2020), mesmo que propondo apresentar exemplos bem sucedidos de ações educacionais no mundo para o Brasil, ateve-se, prioritariamente, às propostas de atividades digitais e dependentes de internet.

A nota do TPE (2020), ao desconsiderar, preliminarmente, a educação infantil pelos motivos mencionados na página 05, acaba impactando no mapeamento das chamadas "estratégias das redes" (TPE, 2020, p.4) estaduais e municipais, pois, é sabido que conforme o inciso V do Art. 11 da LDB 9394/96, o oferecimento da educação infantil é de responsabilidade dos municípios, sendo assim, a maioria deles pode não ter apresentado nenhuma ação - como descrito no gráfico 1.2 (TPE, 2020, p.04) - em função de não atuarem com as outras etapas da educação básica (ensino fundamental e ensino médio) e não por incompetência ou inatividade deliberada.

Ainda com relação às notas aqui analisadas não considerarem a educação infantil, salvo menção feita pelo Banco Mundial (2020, p.01) sobre abertura de escolas infantis para crianças de trabalhadores dos setores essenciais na Finlândia, consideramos que no mês de abril de 2020, quando as referidas notas foram publicadas, ainda havia uma expectativa de reabertura das escolas até o mês de agosto de 2020, porém, dada a condição de crescimento do número de casos e mortes ${ }^{1}$ por Covid-19 no Brasil, a reabertura das escolas não tem previsão pelas autoridades paulistas ${ }^{2}$. Sendo assim, conforme enfatizado na nota do TPE (2020), cabe-nos os desafios para a normatização da vida escolar de milhões de estudantes brasileiros, inclusive, da Educação Infantil.

Então, na sequência, faremos uma sucinta retomada da legislação nacional frente às exigências e possibilidades que vêm sendo normatizadas para a educação brasileira nesse período de excepcionalidade, bem como, ressaltando os desdobramentos observados no 
Sistema Municipal de Ensino de Campinas onde, até o presente momento, todas as atividades desenvolvidas têm caráter definido como "mitigador", ou seja, não letivo.

\section{Pontos e contrapontos ao documento orientador publicado pela Secretaria Municipal de Educação de Campinas (SP)}

A Lei de Diretrizes e Bases da Educação Nacional (LDBEN) 9394/96, a qual, no inciso primeiro de seu artigo 24, define que a carga horária mínima anual da Educação Básica, nos níveis Fundamental e Médio, será de oitocentas horas, distribuídas por um mínimo de duzentos dias de efetivo trabalho escolar, excluído o tempo reservado aos exames finais, quando houver.

Já com relação ao ensino a distância, a LDBEN 9394/96, no parágrafo $4^{\circ}$ de seu artigo 32, afirma que: "o Ensino Fundamental será presencial, sendo o ensino a distância utilizado como complementação da aprendizagem ou em situações emergenciais”. (Brasil, 1996)

Ainda com relação ao ensino a distância, a LDBEN 9394/96, em seu artigo 80, afirma que "o poder público incentivará o desenvolvimento e a veiculação de programas de ensino a distância, em todos os níveis e modalidades de ensino, e de educação continuada". (Brasil, 1996)

Além dos artigos e seus respectivos parágrafos da LDBEN 9394/96 supracitados, também ressaltamos o parágrafo 15 do Art. 17 da Resolução CNE/CEB no 03/2018, que aborda as alterações introduzidas na LDBEN pela Lei no 13.415/2017 com relação à Reforma do Ensino Médio, onde os estudantes de Ensino Médio podem cumprir parte da carga horária total de forma a distância (20\% no Ensino Médio regular e 30\% no Ensino Médio noturno).

Já no contexto dos impactos da Pandemia Covid-19 com o fechamento das escolas brasileiras a partir de março de 2020, temos que, no dia de $1^{\circ}$ de abril de 2020, por meio da Medida Provisória $n^{0}$ 934/2020, restrita ao ano letivo afetado pelas medidas para enfrentamento da situação de emergência de saúde pública de que trata a Lei no 13.979 , de 6 de fevereiro de 2020, o poder executivo federal estabeleceu a desobrigação do cumprimento dos 200 dias letivos e a manutenção da exigência do cumprimento da carga horária mínima de 800 horas na Educação Básica (educação infantil, ensino fundamental e ensino médio), a qual, independente das adequações necessárias, também tem exigência de manutenção amparada no parágrafo $2^{\circ}$ do Artigo 23 da LDBEN 9394/96.

Em 18 de agosto de 2020, foi publicada a Lei 14.040/2020 que estabelece normas educacionais excepcionais a serem adotadas durante o estado de calamidade pública reconhecido pelo Decreto Legislativo $\mathrm{n}^{\mathrm{o}}$ 06, de 20 de março de 2020 e altera a Lei 11.947/2020, de 16 de junho de 2009.

A Lei 14.040/2020, em seu inciso I do Art. $2^{\circ}$ continua desobrigando o cumprimento mínimo dos duzentos dias letivos (já anteriormente definido pela MP 934/2020) e acrescenta, também em caráter excepcional, a não obrigatoriedade das 800 horas letivas na Educação Infantil, o que, atende às diversas solicitações contidas no Parecer CNE/CP n ${ }^{\circ}$ 05/2020, as 
quais, enfatizaram não haver previsão legal, nem normativa, para oferta de educação a distância, mesmo em situação de emergência, nesta etapa da Educação Básica.

Amparado no Parecer do CNE/CP 05/2020, o Conselho Municipal de Educação de Campinas, publicou a Res. CME 01/2020 (DOM 24/04/2020), na qual, dispõe quanto à reorganização dos calendários escolares, no âmbito do Sistema Municipal de Ensino de Campinas devido ao surto global da COVID-19, e dá outras providências.

$\mathrm{Na}$ Res. CME 01/2020, foi indicado computar na carga horária de atividade escolar obrigatória, se necessário, as atividades programadas fora da escola, no limite máximo de $15 \%$ do total das 800 horas previstas (MP 934/2020), preservada a natureza da relação professor-aluno e garantido o acesso de todos os envolvidos.

Além disso, o regramento acima do Conselho Municipal de Educação de Campinas, definido para as escolas de educação infantil (públicas e privadas) e para as escolas públicas municipais de ensino fundamental, ainda depende, conforme Parágrafo Único do Art. $4^{\circ}$ da Res. CME 01/2020, de norma complementar a ser publicada pela Secretaria Municipal de Educação.

Para que a norma complementar prevista pela Res. CME 01/2020 seja publicada, a Secretaria Municipal de Educação de Campinas constituiu duas comissões, sendo uma para o ensino fundamental (Portaria SME/FUMEC n ${ }^{\circ}$ 02/2020, DOM de 30/04/2020) e outra para a Educação Infantil (Portaria SME no 22/2020, DOM de 15/05/2020), as quais foram formadas por supervisores de ensino, coordenadores pedagógicos, diretores de escola e orientadores pedagógicos com o propósito de formularem, cada qual, propostas de calendários escolares com a devida previsão de como serão consideradas as chamadas atividades escolares letivas não presenciais, no limite máximo de $15 \%$ das 800 horas letivas e na melhor forma de preservar a natureza da relação professor-aluno e garantir o acesso de todos.

Porém, além dos trabalhos das comissões supracitadas ainda não terem resultado em publicação de norma complementar conforme prevê a Res. CME 01/2020, temos a mudança trazida pela Lei Federal 14.040/2020 desobrigando o cumprimento das 800 horas letivas na educação, bem como, o Parecer CNE/CP 11/2020, aprovado em 07 de julho de 2020 que dá orientações educacionais para a realização de aulas e atividades pedagógicas presenciais e não Presenciais no contexto da Pandemia Covid 19.

Sendo assim, voltando ao conceito de "abstracionismo pedagógico" apresentado por Azanha (1992) e considerando o fato de que os discursos abstratos sobre educação podem ter um efeito paralisante sobre a própria ação educativa, destacamos alguns elementos a serem considerados como possíveis justificativas para que a normatização complementar prevista na Res. CME 01/2020 ainda não tenha sido publicada:

- Do documento "Princípios orientadores para a atuação dos profissionais do DEPE e CEIs durante o isolamento social devido à Covid-19", de 15 de abril de 2020 (CAMPINAS, 2020b), destacamos: 
O ambiente familiar e sua dinâmica potencializam experiências para as crianças de natureza diferente das experiências potencializadas na instituição de Educação Infantil e ambas são importantes para a vida da criança, desde bebê - de modo que nem um e nem outro ambiente poderia ser reproduzido fora de seus espaços originais, mesmo que de alguma forma isso fosse pretendido. Trata-se aqui, talvez, de uma das questões nevrálgicas de nossa temática, posto que se não há possibilidade de reprodução da dinâmica da casa na instituição de Educação Infantil, tampouco desta, na casa de cada família. (Campinas, 2020b, s/n)

O fragmento acima ressalta, como questão "nevrálgica" a não possibilidade de reprodução da dinâmica da casa na instituição de Educação Infantil e tampouco desta, na casa de cada família. Sendo assim, gostaríamos de considerar dois aspectos:

a) As chamadas atividades não presenciais previstas na Res. CME 01/2020, não indicam e muito menos têm relação com qualquer tipo de transformação ou ação que considere as casas de cada família como um ambiente escolar;

b) As atividades de caráter mitigador que estão sendo desenvolvidas e propostas pelas equipes educacionais dos Centros de Educação infantil têm se valido de diferentes meios, digitais e analógicos, com o devido cuidado para não serem invasivas nos ambientes familiares (princípio 4), manterem o vínculo entre família e CEI (princípio 5) e respeitando o Projeto Pedagógico, bem como, o protagonismo dos educadores (princípio 6).

Outro fragmento do documento Princípios Orientadores (Campinas, 2020b) ressalta que "qualquer ação deflagrada pela SME centralmente e/ou pelos próprios CEIs será acessível a TODAS as crianças matriculadas nos CEIs e suas famílias. (Campinas, 2020b, s/n)

Sendo assim, destacamos que os Centros de Educação Infantil, embora tenham sido, inicialmente, autorizados pela Secretaria Municipal de Educação de Campinas (SME) a cumprirem apenas os tempos de trabalho pedagógico coletivo, pois todos os tempos de aula estavam suspensos para essa etapa da educação básica até meados de agosto de 2020, têm, com diferentes recursos (analógicos e digitais), buscado oferecer atividades para todas as crianças; porém, sabemos que nem mesmo em tempos de "normalidade" o acesso é realizado pela totalidade das famílias, bem como, o próprio Parecer CNE $n^{\circ}$ 05/2020 flexibilizou a consideração de frequência mínima das crianças na educação infantil conforme a realidade verificada em cada sistema.

Além disso, em que pese, se inicialmente a imposição legal para o cumprimento das 800 horas letivas em todas as etapas da educação básica estava presente na MP 934/2020 e foi retirada pela Lei Federal 14.040/2020 da educação infantil, bem como, dado o avançado dos dias e a falta de previsão objetiva do retorno às atividades nos ambientes escolares, cabe alertar que:

a) a falta de regramento específico que considere, o quanto antes, as atividades remotas nas escolas do sistema municipal de ensino de Campinas, negando qualquer grau de autonomia às práticas escolares concretas em um período específico de excepcionalidade dado pela Pandemia Covid-19, coloca em situação delicada as futuras condições para o cumprimento obrigatório das referidas horas letivas no ensino fundamental; 
b) prejudica a vida escolar dos estudantes e as possibilidades reais de reposição quando do retorno em função da melhor forma de garantir o número de profissionais, os recursos financeiros e as próprias condições de trabalho com segurança sanitária para os profissionais da educação, crianças, jovens e adultos do sistema de ensino municipal de Campinas;

c) a não normatização das atividades remotas como letivas no ensino fundamental o quanto antes, guardadas as devidas considerações sobre a necessidade de garantia do acesso dos(as) estudantes, porque haverá quem não terá acesso às plataformas digitais disponíveis, de fato, não resultará na melhor forma de resguardar o direito à educação, pois, é no regramento claro e objetivo das práticas de atuação das escolas que, inclusive, irão ser identificados aqueles que não estão tendo acesso e, assim, de maneira mais eficiente, criar novas estratégias de inclusão para todos.

\section{Considerações Finais}

Podemos ressaltar que tanto a nota do Banco Mundial (2020), como a nota do TPE (2020), trouxeram como principal objetivo das ações propostas a preocupação com a aprendizagem dos estudantes, ou seja, o que pode ser relacionado à ascensão do conceito de aprendizagem apontado por Biesta (2012, p.815), que chama de "nova linguagem de aprendizagem", a qual, como um conceito individualista, manifesta-se na redefinição do ensino como facilitação da aprendizagem e da educação como o provimento de oportunidades de aprendizagem ou de experiências de aprendizagem.

Segundo Biesta (2012), o resultado da ascensão da aprendizagem em detrimento de uma definição ampla de educação, resultaria em uma combinação de tendências, das quais, podemos destacar e contrapor à realidade dos tempos de impactos da Pandemia Covid-19 na educação, tal como:

- A crítica pós-moderna à ideia que os processos educacionais podem e devem ser controlados por professores: nas notas aqui analisadas, o papel do professor foi ressaltado como primordial em todas as ações propostas para continuidade do processo ensino-aprendizagem;

- A chamada explosão silenciosa da aprendizagem como evidenciada pelo enorme crescimento da aprendizagem informal na vida das pessoas: As notas apresentam grande preocupação com a aprendizagem realizada pelos estudantes em função dos conteúdos escolares e no contato com os(as) professores(as), inclusive, o Banco Mundial (2020, p. 02) deixa claro que: "A ausência de interação entre estudantes e professores rompe o processo de aprendizagem e se a pandemia durar muitas semanas, não será possível recuperar o tempo perdido quando as escolas reabrirem."

- A erosão do Estado do Bem-estar e a subsequente ascensão das políticas de educação neoliberais nas quais o indivíduo é priorizado em relação a outros fatores, o que muda a responsabilidade pela aprendizagem continuada (ao longo da vida) do provedor para 
o consumidor, transformando a educação de um direito, em um dever: Os dados brasileiros de acesso à internet, de acesso a equipamentos de tecnologia da informação (TICs), de apoio familiar para o estudo em casa, de formação para trabalho com tecnologias educacionais para os professores e de escolas com equipamentos e uso de internet apresentados nas notas analisadas, revelam uma grande desigualdade socioespacial que remete à responsabilidade constitucional do Estado (poder público) na garantia do direito à educação, mesmo em tempos de calamidade pública - Pandemia Covid-19, promovendo todos os meios necessários para o acesso e permanência dos estudantes nas escolas.

Além disso, segundo Larrosa (2018, p.204), a substituição da força de trabalho pela força de aprendizagem como recurso produtivo fundamental do capitalismo cognitivo é, portanto, reveladora das tentativas de converter a sala de aula em uma máquina (ou um ambiente) de "aprendizagem em geral" na qual o "aprender a aprender" seria a formulação mais nítida.

Mesmo com a defesa das práticas de ensino a distância nesse período excepcional de isolamento social em função da situação de calamidade sanitária imposta pela Pandemia Covid-19, colocamo-nos juntos com a total rejeição de todas as tentativas de desinstitucionalizar a educação, ou seja, segundo Larrosa (2018), de acabar com a escola e com a sala de aula por meio do argumento de que se aprende em qualquer lugar e a qualquer hora, de que a aprendizagem se confunde com a totalidade da vida.

Nesse sentido, Marina Garcés (apud Larrosa, 2018) diz que:

A escola do futuro já começou a ser construída, e não a estão pensando os estados nem as comunidades, mas sim as grandes empresas de comunicação e os bancos. Não tem paredes nem valas, mas plataformas online e professores 24 horas por dia. Não lhe fará falta ser excludente porque será individualizadora de talentos e de percursos vitais e de aprendizagem. Praticará a universalidade sem igualdade: uma ideia em que temos que começar a pensar porque será, se já não é, a condição educativa do nosso tempo. (Gaecés, M. apud Larrosa, 2018, p.204-205)

Então, não é de forma despretensiosa que as notas aqui analisadas foram produzidas por uma instituição internacional financeira, no caso o Banco Mundial e a outra - Todos Pela Educação (TPE) - uma Organização da Sociedade Civil, que tem como mantenedores as principais instituições financeiras privadas do Brasil, ao passo que, apesar das diferenças encontradas em suas análises para os impactos e soluções na educação brasileira frente à Pandemia Covid-19, fica claro o interesse de intervir e até mesmo fomentar o caminho para essa universalidade sem igualdade em uma suposta transição para a educação por meio de plataformas online.

Olhando para os desdobramentos de toda essa discussão sobre o ensino a distância, suas possibilidades e desigualdades em uma perspectiva de sua total excepcionalidade, buscamos problematizar os atuais processos de normatização explorados a partir da legislação educacional brasileira, seus caminhos e dificuldades para subsidiar com a devida defesa pela 
vida, as ações das escolas de educação infantil e ensino fundamental do sistema de ensino de Campinas (SP), no cumprimento da legislação em vigor, por meio das atividades não presenciais que ainda precisam ser regulamentadas pela Secretaria Municipal de Educação de Campinas (SP).

Por fim, não deixando de reconhecer aquilo que, talvez, em função do próprio fechamento das escolas por conta da Pandemia Covid-19, de maneira contraditória, fica cada vez mais evidente, ou seja: o caráter central da escola e da sala de aula. (Larrosa, 2018, p.184).

\section{Notas}

1. "O Brasil completou nesta quinta-feira 100 dias desde que registrou o primeiro caso de coronavírus, confirmado pelo Ministério da Saúde em 26 de fevereiro. Desde então, a curva de crescimento de infectados e óbitos no país avança em níveis assustadores, o que preocupa a população e exige ações ainda mais concretas, num momento em que o poder público começar liberar gradualmente as atividades econômicas." Fonte: Jornal Estado de Minas. Disponível em :https://www.em.com.br/app/noticia/nacional/2020/06/04/interna_nacional,115386/brasil-completa-100-dias-de-covid -19-com-maior-curva-ascendente-no-mun.shtml. Acessado em 13/06/2020.

2. "Após divulgar reabertura das escolas para julho, secretaria de Educação de SP recua e diz que retorno não tem data definida”. Fonte: G1. Disponível em: https://g1.globo.com/sp/sao-paulo/noticia/2020/06/04/governo-de-sp-anunciareabertura-das-escolas-a-partir-de-julho.ghtml. Acessado em: 13/06/2020.

\section{Referências bibliográficas}

AZANHA, J.M.P. Uma ideia de pesquisa educacional. São Paulo: Edusp, 1992.

BANCO MUNDIAL. "Políticas Educacionais na Pandemia da COVID-19: O que o Brasil pode aprender com o resto do mundo?". Nota técnica, abril/2020. Disponível em: <https:/ /www.worldbank.org/pt/country/brazil/publication/brazil-education-policy-covid-19-coronaviruspandemic>. Acessado em junho de 2020.

BIESTA, G. Boa educação na era da mensuração. Cadernos de Pesquisa, v.42 n.147, p.808-825 set./dez. 2012. Disponível em: https://www.scielo.br/pdf/cp/v42n147/09.pdf. Acessado em junho de 2020.

BRASIL. Decreto 9.057/2017, que Regulamenta o art. 80 da Lei no 9.394, de 20

de dezembro de 1996, que estabelece as diretrizes e bases da educação nacional. Disponível em: http://www.planalto.gov.br/ccivil_03/_ato2015-2018/2017/decreto/d9057.htm. Acessado em junho de 2020.

Lei de Diretrizes e Bases da Educação Nacional. Lei no 9.394. 1996.

Medida Provisória no 934/2020, que institui Normas excepcionais

sobre a duração do ano letivo. Disponível em: https://www.congressonacional.leg.br/materias/medidasprovisorias/-/mpv/141349. Acessado em junho de 2020.

. Ministério da Educação. Conselho Nacional de Educação Conselho Pleno. Parecer CNE/CP no 11/2020.

Disponível

em: http://portal.mec.gov.br/index.php?option=com_docman\&view=download\&alias=148391-pcp01120\&category_slug=julho-2020pdf\&Itemid=30192. Acessado em junho de 2020.

Ministério da Educação. Conselho Nacional de Educação Conselho Pleno. Parecer CNE/CP no 05/2020.

Disponível

em: 
http://portal.mec.gov.br/index.php?option=com_docman\&view=download\&alias=145011-pcp00520\&category_slug=marco-2020-pdf\&Itemid=30192. Acessado em junho de 2020.

CAMPINAS. Conselho Municipal de Educação. Resolução CME n⿳0 01/2020, de 16 de abril de 2020. Publicada no DOM em 24 de abril de 2020, p. 02. Disponível em: http://portal.mec.gov.br/seed/arquivos/pdf/tvescola/leis/lein 9394.pdf. Acessado em junho de 2020.

CAMPINAS. Secretaria Municipal de Educação." Princípios orientadores para a atuação dos profissionais do DEPE e CEIs durante o isolamento social devido à Covid-19." Disponível em: https://sites.google.com/educa.campinas.sp.gov.br/smeteletrabalho/educa\%C3\%A7\%C3\%A3oinfantil/propostas-de-trabalho?authuser=0. Acessado em agosto de $2020 \mathrm{~b}$.

LARROSA, J. Esperando não se sabe o quê: sobre o ofício de professor. Belo Horizonte: Autêntica Editora, 2018.

POPKEWITZ, T; LINDBLAD, S. A fundamentação estatística, o governo da educação e a inclusão e exclusão sociais. Ed. Soc. Campinas, v. 37, no 136, p.727-754, jul.-set., 2016.

TODOS PELA EDUCAÇÃO. "Análise: ensino a distância na educação básica frente à Pandemia da Covid-19”. Nota técnica, abril/2020. Disponível em: https://www.todospelaeducacao.org.br/_uploads/_posts/425.pdf. Acessado em junho de 2020.

\section{Correspondência}

Juliano Pereira de Mello: É Coordenador Pedagógico de carreira junto à Secretaria Municipal de Educação de Campinas (SP), Professor da Faculdade de Geografia - Pontifícia Universidade Católica de Campinas e Doutorando junto ao Programa de Pós Graduação em Educação da PUC Campinas.

E-mail: juliano.mello@puc-campinas.edu.br

Artur José Renda Vitorino: É Professor titular da Pontifícia Universidade Católica de Campinas e pertencente ao corpo permanente de seu Programa de Pós Graduação em Educação.

E-mail: arturvitorino@uol.com.br

Texto publicado em Currículo sem Fronteiras com autorização dos autores 